\title{
Interactions of alfalfa hay and sodium propionate on dairy calf performance and rumen development
}

\author{
H. Beiranvand, ${ }^{\star 1}$ G. R. Ghorbani, ${ }^{\star}$ M. Khorvash, ${ }^{\star}$ A. Nabipour,† M. Dehghan-Banadaky,‡ A. Homayouni, ${ }^{*}$ \\ and S. Kargar*2 \\ ${ }^{*}$ Department of Animal Sciences, College of Agriculture, Isfahan University of Technology, Isfahan 84156-83111, Iran \\ †Department of Basic Sciences, College of Veterinary Medicine, Ferdowsi University of Mashhad, Mashhad 91779-48974, Iran \\ ‡Department of Animal Sciences, University College of Agriculture and Natural Resources, University of Tehran, Karaj 31587-77871, Iran
}

\section{ABSTRACT}

The objective of this experiment was to investigate the effects of different levels of alfalfa hay $(\mathrm{AH})$ and sodium propionate (Pro) added to starter diets of Holstein calves on growth performance, rumen fermentation characteristics, and rumen development. Forty-two male Holstein calves ( $40 \pm 2 \mathrm{~kg}$ of birth weight) were used in a complete randomized design with a $3 \times 2$ factorial arrangement of treatments. Dietary treatments were as follows: (1) control = concentrate only; (2) Pro $=$ concentrate with $5 \%$ sodium propionate [dry matter (DM) basis]; (3) $5 \% \mathrm{AH}=$ concentrate $+5 \%$ alfalfa hay (DM basis); (4) $5 \% \mathrm{AH}+$ Pro $=$ concentrate $+5 \%$ alfalfa hay $+5 \%$ sodium propionate (DM basis); (5) $10 \% \mathrm{AH}=$ concentrate $+10 \%$ alfalfa hay (DM basis); and (6) $10 \% \mathrm{AH}+$ Pro $=$ concentrate $+10 \%$ alfalfa hay $+5 \%$ sodium propionate (DM basis). All calves were housed in individual pens bedded with sawdust until 10 wk of age. They were given ad libitum access to water and starter throughout the experiment and were fed $2 \mathrm{~L}$ of milk twice daily. Dry matter intake was recorded daily and body weight weekly. Calves from the control, $10 \% \mathrm{AH}$, and $10 \% \mathrm{AH}+$ Pro treatments were euthanized after wk 10, and rumen wall samples were collected. Feeding of forage was found to increase overall dry matter intake, average daily gain, and final weight; supplementing sodium propionate had no effect on these parameters. Calves consuming forage had lower feed efficiency than those on the Pro diet. Rumen fluid in calves consuming forage had higher $\mathrm{pH}$ and greater concentrations of total volatile fatty acids and molar acetate. Morphometric parameters of the rumen wall substantiated the effect of AH supplementation, as plaque formation decreased macroscopically. Overall,

Received October 31, 2012.

Accepted July 22, 2013.

${ }^{1}$ Corresponding author: hamedbeiran669@gmail.com

${ }^{2}$ Current address: Department of Dairy Science, College of Agriculture and Life Sciences, University of Wisconsin-Madison, Madison 53706-1284. the interaction between forage and sodium propionate did not affect calf performance parameters measured at the end of the experiment. Furthermore, inclusion of $\mathrm{AH}$ in starter diets positively enhanced the growth performance of male Holstein calves and influenced both the macroscopic and microscopic appearances of the rumen wall. These benefits, however, were small when only sodium propionate was offered.

Key words: calf, forage, rumen development, sodium propionate

\section{INTRODUCTION}

Early weaning strategies in dairy calves depend on the consumption of a starter diet and associated development of the rumen. There is disagreement regarding the chemical and physical characteristics of starter diets and the optimal rate of forage provision to preruminant calves (Coverdale et al., 2004; Suarez et al., 2007). Feed concentrates have been formulated for calves to maximize not only DMI and ADG, but also VFA production (Suarez et al., 2006). Ruminal fermentation of dietary concentrates and their end products (especially butyrate and propionate) play a central role in ruminal epithelium differentiation and papilla development (Flatt et al., 1958; Mentschel et al., 2001). In addition, increasing ruminal propionate production by feeding a high-concentrate diet may be associated with improved animal performance and rumen development via its indirect effect on endocrine hormones (Peiris et al., 1998; Liu et al., 2010). However, overloading butyrate and propionate may promote keratinization of papillae by increasing the mitogenic rate and decreasing the apoptosis rate of the epithelium (Flatt et al., 1958; Mentschel et al., 2001).

Because of the lower digestibility of forage in the rumen of calves, the VFA produced are insufficient for optimal growth of papillae and thus, rumen development is slowed (Coverdale et al., 2004). Moreover, an increased forage level in calf diets is reportedly accompanied by decreased ruminal propionate (Suarez et al., 2007; van Ackerena et al., 2009). Research has shown that forage 
has the potential to encourage early rumination and enhance rumen $\mathrm{pH}$ and rumen muscle strength, while also reducing cancerous proliferation and keratinization of rumen papilla (Tamate et al., 1962; Klein et al., 1987; Beharka et al, 1998). On the other hand, large amounts of forage in the feed leads to decreased DMI and ADG in calves (Hill et al., 2008, 2009, 2010). A number of studies, however, have reported that feeding forage increases starter intake by the calf and enhances muscular development of the rumen (Coverdale et al., 2004; Khan et al., 2011; Castells et al., 2012).

Based on the above considerations, we hypothesized that adding propionate to diets with alfalfa hay could enhance calf performance and improve rumen conditions. We further postulated that simultaneous use of propionate and forage would be more effective than either offered separately. The objective of current experiment was to examine the effects of, and interactions between, different levels of alfalfa hay and sodium propionate on performance, weaning age, and ruminal fermentation characteristics in calves. Furthermore, macroscopic and microscopic observations in selected treatments were used to determine the influence of the interaction between forage (as the physical factor) and propionate (as the chemical factor) on rumen development.

\section{MATERIALS AND METHODS}

The experiment was conducted on a local dairy farm (FKA Agri-Animal Production Co., Isfahan, Iran). Calves were cared for according to the guidelines of the Iranian Council of Animal Care (1995).

\section{Animals, Housing, and Diets}

Forty-two male Holstein calves $(40 \pm 2 \mathrm{~kg}$; mean \pm SD) were separated from their mothers, weighed, fed colostrum within 6 -h after birth for the first $3 \mathrm{~d}$ of age, and then moved to individual pens $(1.2 \mathrm{~m} \times 2.4 \mathrm{~m})$ bedded with sawdust. A complete randomized design with a $3 \times 2$ factorial arrangement was used in the experiments, with different levels of alfalfa hay $(\mathbf{A H})$ and propionate (Pro) as the experimental factors. The dietary treatments included concentrate and variable ratios of chopped AH with or without sodium propionate salt (143473, Panrac Co., Barcelona, Spain). Dietary treatments were as follows: (1) Control = concentrate only; (2) Pro $=$ concentrate $+5 \%$ sodium propionate (DM basis); (3) $5 \% \mathrm{AH}=$ concentrate $+5 \%$ alfalfa hay (DM basis); (4) $5 \% \mathrm{AH}+$ Pro $=$ concentrate $+5 \%$ alfalfa hay $+5 \%$ sodium propionate (DM basis); (5) $10 \% \mathrm{AH}=$ concentrate $+10 \%$ alfalfa hay $(\mathrm{DM}$ basis); and (6) $10 \% \mathrm{AH}+$ Pro $=$ concentrate +
$10 \%$ alfalfa hay $+5 \%$ sodium propionate (DM basis). Starter diets and fresh water were provided ad libitum throughout the experimental period. Concentrate was offered in meal form and $\mathrm{AH}$ was chopped by a machine (Golchin Trasher Hay Co., Isfahan, Iran) with a geometric mean particle size of $2.6 \mathrm{~mm}$ on the basis of Penn State Particle Separator box values. All diets were formulated to be isonitrogenous and isocaloric and met NRC (2001) requirements for calf nutrients. The ingredient and nutrient compositions of the starters are presented in Table 1. The starter diets were high in grain content and the $\mathrm{AH}$ contained $16 \% \mathrm{CP}$ and $40 \%$ NDF. All calves were fed pasteurized waste milk at a rate of $10 \%$ of their initial BW (4 kg/head per day). Milk (2.7\% protein, $3.4 \%$ fat, and SCC of $801 \times 1,000$ cells $/ \mathrm{mL}$ ) was approximately $38^{\circ} \mathrm{C}$ when fed via mobile metal bottles (2-L capacity) twice daily at 0800 and $1500 \mathrm{~h}$.

\section{Data Collection, Sampling, and Laboratory Analyses}

Starter offered and refused were recorded daily for each calf to determine DMI. Calves were initially weighed at approximately $1200 \mathrm{~h}$ on $\mathrm{d} 0$ of the experiment and every $7 \mathrm{~d}$ until the end of the experiment period (d 70). Feed efficiency (FE) was calculated as kilograms of BW gain per kilogram of total DMI. The structural growth indices considered included body height (distance from base of the rear feet to shoulder bones), hip width (distance between hip bone), and hip height, all measured according to Lesmeister and Heinrichs (2005). These parameters were recorded at birth, weaning, and at the end of the experimental period. Calves were weaned when they consumed $1 \mathrm{~kg}$ of their allocated starter for 3 consecutive days.

\section{Rumen Fluid Sampling and VFA Analyses}

On d 35 and 70 of age, ruminal contents were collected approximately $3 \mathrm{~h}$ postfeeding using a stomach tube. Sample $\mathrm{pH}$ was determined immediately using a pH meter (HI 8314 membrane pH meter, Hanna Instruments, Villafranca, Italy). The ruminal contents were subsequently squeezed through 4 layers of cheesecloth to collect rumen fluid samples $(10 \mathrm{~mL})$ in tubes, which were then placed on ice and transferred to the laboratory where they were acidified with $3 \mathrm{~mL}$ of $25 \%$ metaphosphoric acid and stored $\left(-20^{\circ} \mathrm{C}\right)$ until analyzed for VFA by gas chromatography $(0.25 \times 0.32 \mathrm{~m}, 0.3 \mu \mathrm{m}$ i.d. fused-silica capillary, model no. CP-9002 Vulcanusweg 259 a.m., Chrompack, Delft, the Netherlands).

\section{Rumen Tissue Sampling and Analyses}

On d 70, 9 calves from selected treatments (control, $10 \% \mathrm{AH}$, and $10 \% \mathrm{AH}+$ Pro; 3 calves per treatment) 
Table 1. Ingredients and chemical composition (\% of DM unless otherwise noted) of experimental starter feeds

\begin{tabular}{|c|c|c|c|c|c|c|}
\hline Item & \multicolumn{6}{|c|}{ Treatment $^{1}$} \\
\hline Alfalfa hay & - & - & 5.0 & 5.0 & 10.0 & 10.0 \\
\hline Corn grain, ground & 61.2 & 60.0 & 57.2 & 56.2 & 54.2 & 54.2 \\
\hline Barley grain, ground & 7.0 & 2.0 & 7.0 & 2.0 & 5.0 & - \\
\hline Dicalcium phosphate & 0.6 & 0.8 & 0.6 & 0.6 & 0.6 & 0.6 \\
\hline Vitamin and mineral premix ${ }^{2}$ & 0.3 & 0.3 & 0.3 & 0.3 & 0.3 & 0.3 \\
\hline Sodium propionate & - & 5.0 & - & 5.0 & - & 5.0 \\
\hline \multicolumn{7}{|l|}{ Composition } \\
\hline DM, \% & 89.00 & 88.00 & 89.00 & 89.00 & 89.00 & 89.00 \\
\hline $\mathrm{CP}$ & 20.10 & 20.30 & 20.30 & 19.80 & 20.30 & 19.70 \\
\hline $\mathrm{ME},{ }^{3} \mathrm{Mcal} / \mathrm{kg}$ & 3.28 & 3.31 & 3.20 & 3.24 & 3.42 & 3.43 \\
\hline $\mathrm{NE}_{\mathrm{G}},{ }^{3} \mathrm{Mcal} / \mathrm{kg}$ & 1.57 & 1.58 & 1.58 & 1.57 & 1.60 & 1.60 \\
\hline
\end{tabular}

${ }^{1}$ Control $=$ concentrate only with no forage and sodium propionate supplemented; Pro $=$ concentrate $+5 \%$ sodium propionate $; 5 \%$ AH $=$ concentrate $+5 \%$ alfalfa hay; $5 \% \mathrm{AH}+$ Pro $=$ concentrate $+5 \%$ alfalfa hay $+5 \%$ sodium propionate; $10 \% \mathrm{AH}=$ concentrate $+10 \%$ alfalfa hay; $10 \% \mathrm{AH}+$ Pro $=$ concentrate $+10 \%$ alfalfa hay $+5 \%$ sodium propionate.

${ }^{2}$ Contained per kilogram of supplement: 250,000 IU of vitamin A, 50,000 IU of vitamin D, 1,500 IU of vitamin E, $2.25 \mathrm{~g}$ of Mn, $120 \mathrm{~g}$ of Ca, 7.7 $\mathrm{g}$ of Zn, $20 \mathrm{~g}$ of P, $20.5 \mathrm{~g}$ of Mg, $186 \mathrm{~g}$ of Na, $1.25 \mathrm{~g}$ of Fe, $3 \mathrm{~g}$ of S, $14 \mathrm{mg}$ of Co, $1.25 \mathrm{~g}$ of Cu, $56 \mathrm{mg}$ of I, and $10 \mathrm{mg}$ of Se.

${ }^{3}$ Calculated from NRC (2001).

were euthanized to collect digestive tract samples. After removing the digestive tract contents, samples were taken for histological examination from different parts of the rumen including the caudal and ventral portions of the caudoventral blind sac, the cranial and caudal parts of the dorsal sac, and the cranial part of the ventral sac (Figures 1 and 2), according to Lesmeister et al. (2004). The samples were then flushed with normal saline and fixed in 10\% buffered formalin (Merck, Darmstadt, Germany) for 96 h. Tissue samples were then dehydrated and cleared by a series of graded alcohols and xylene before being embedded in paraffin. Sections $(6 \mu \mathrm{m})$ were stained with hematoxylin and eosin for observation under a CX21 light microscope (Olympus, Tokyo, Japan). An Olympus (U-TVO $63 \mathrm{XC}$ ) camera mounted on the microscope was used to take microphotographs. The length and width of the papillae and the thicknesses of the epithelium, keratin layer, muscle layers, and rumen wall were measured using image analyses computer software (DP2-BSW, version 1.3; Olympus).

\section{Statistical Analyses}

Dry matter intake, ADG, and FE were analyzed separately for wk 1 to 6 , wk 7 to 10 , and over the entire experimental period as a complete randomized design in a $3 \times 2$ factorial arrangement with 3 levels of $\mathrm{AH}$ $(0,5$, and $10 \%)$ and 2 levels of sodium propionate $(0$ and 5\%). Dry matter intake, ADG, FE, and ruminal fermentation characteristics were statistically analyzed using the following model:

$$
\begin{aligned}
Y_{i j k l}= & \mu+F_{i}+P_{j}+W_{k}+(F \times W)_{i k}+(P \times W)_{j k} \\
& +(F \times P)_{i j}+(F \times P \times W)_{i j k}+\beta\left(X_{i}-\bar{X}\right)+\varepsilon_{i j k l},
\end{aligned}
$$

where $Y_{i j k l}$ is the dependent variable; $\mu$ is the average experimental value; $F_{i}$ is the effect of forage $i(i=0,5$, and $10 \%) ; P_{j}$ represents the effect of propionate $j(j=$ diet with or without propionate); $W_{k}$ is the effect of week $k$ ( $k=$ number of weeks $) ;(F \times P)_{i j}$ designates the effect of the interaction between forage and propionate; $(F \times W)_{i k}$ designates the effect of the interaction between forage and week; $(P \times W)_{j k}$ represents the effect of the interaction between propionate and week; $(F \times$ $P \times W)_{i j k}$ is the tripartite effect of forage, propionate, and week; $\beta\left(X_{i}-\bar{X}\right)$ designates the covariate variable, where $\beta$ is the regression coefficient relating the covariate factor to the variable measured, $X_{i}$ is the covariate factor for the $i$ th subject, and $\bar{X}$ is the overall mean of covariate factor; and $\varepsilon_{i j k l}$ is the error term. 


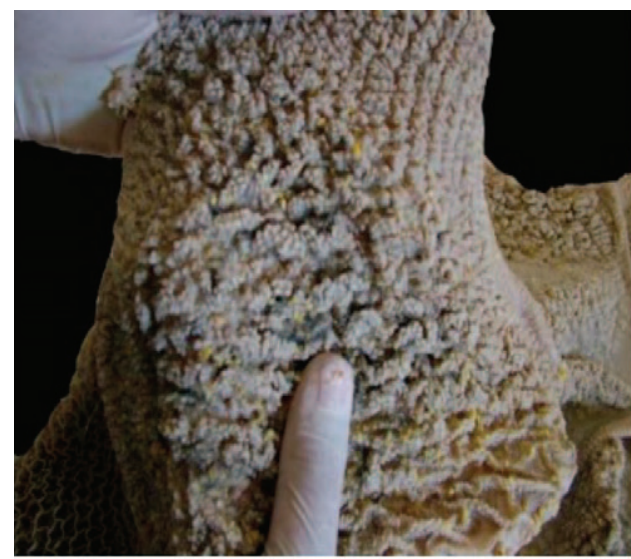

Control

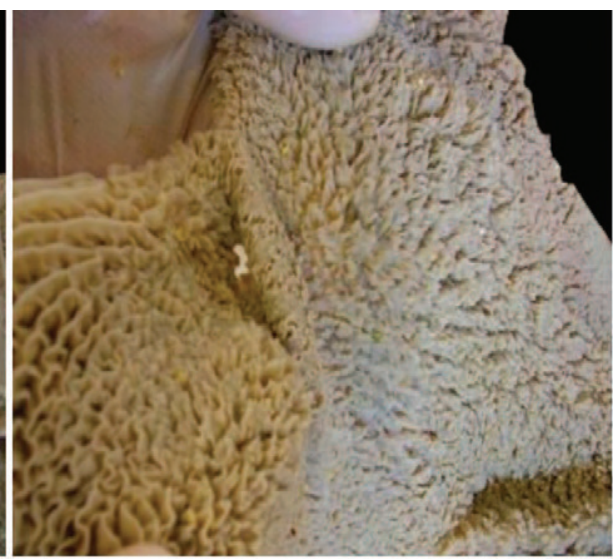

$10 \% \mathrm{AH}$

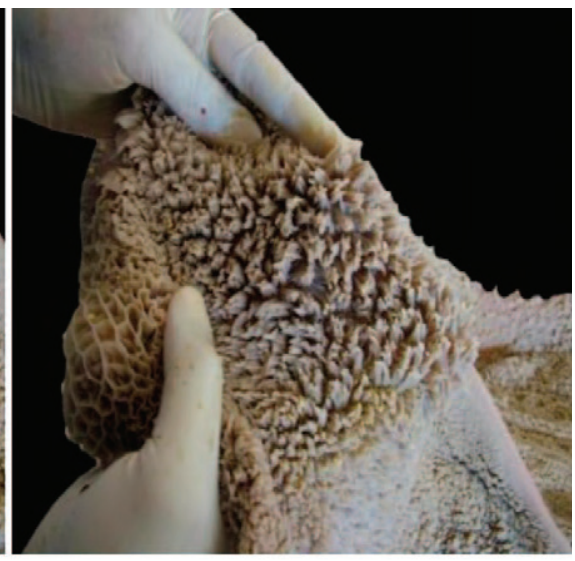

$10 \% \mathrm{AH}+$ Pro

Figure 1. Interior of rumen of selected treatments. Control = concentrate only with no forage and sodium propionate supplemented; $10 \% \mathrm{AH}$ $=$ concentrate $+10 \%$ alfalfa hay; $10 \% \mathrm{AH}+\mathrm{Pro}=$ concentrate $+10 \%$ alfalfa hay $+5 \%$ sodium propionate. Color version available in the online PDF.

Calf within treatment was included as a random effect to investigate the main effect of the treatment. Week was modeled as a repeated measurement by using an autoregressive type 1 covariance structure. The lowest level of the Bayesian information criterion (fit statistic) was used to select the covariance structure of the model for each parameter. Weaning day and initial weight were included in the model as covariates for weaning weight. In addition, weaning weight and initial weight were included as covariates for final weight. For skeletal growth parameters, weaning age was included in the model as a covariate. The differences among treatment means were determined using the Tukey multiple range test. Significance was declared at $P \leq 0.05$ unless otherwise noted, and trends declared at $0.05<P \leq 10$.

Rumen tissue parameters were analyzed as a complete randomized design. Continuous data were subjected to ANOVA according to the following model:

$$
Y_{i j}=\mu+\operatorname{diet}_{i}+\varepsilon_{i j}
$$

where $Y_{i j}$ is the dependent variable; $\mu$ is the average experimental value; diet is the effect of dietary treatment $i$ ( $i$ represents the control diet, $10 \% \mathrm{AH}$, and $10 \% \mathrm{AH}+$ Pro; $i=1,2,3$, respectively); and $\varepsilon_{i j}$ is the error term.

\section{RESULTS AND DISCUSSION}

\section{Effects of $\mathrm{AH}$ on Performance}

The values for DMI, ADG, FE, and weaning day, as well as weaning and final weights, are presented in Table 2. Starter intake and total DMI increased with the age of the calves and were affected by $\mathrm{AH}$ additions to the diets. Calves fed $10 \% \mathrm{AH}$ and $10 \% \mathrm{AH}+$ Pro exhibited greater $(P<0.01)$ DMI values than those fed the control, Pro, and 5\% AH + Pro diets. In this study, the higher values of DMI in calves fed the $\mathrm{AH}$ diets might have resulted from the higher $\mathrm{pH}$ values in the rumen fluid. Previous studies have shown that decreased ruminal $\mathrm{pH}$ is associated with decreased starter consumption in calves (Suarez et al., 2006; Khan et al., 2011).

Average daily gain in calves fed the $10 \% \mathrm{AH}+$ Pro diet was greater $(P<0.05)$ than that for calves fed the Pro and 5\% AH diets. Final weight was greater $(P<$ 0.01 ) in calves fed the $10 \% \mathrm{AH}$ and $10 \% \mathrm{AH}+$ Pro diets than in those in other treatments. Weaning weight was not affected by treatment.

Forage inclusion in diets has been reported to have mixed effects on ADG: Hill and colleagues $(2008,2010)$ reported a decreasing effect, whereas others (Coverdale et al., 2004; Khan et al., 2011; Castells et al., 2012) reported an increasing effect on ADG in calves. The differences in forage source, quantity, and particle size might have influenced these differences in ADG and final BW compared with the current study.

Consistent with the linear decline in FE with increasing percentage of hay inclusion reported by Hill et al. (2008), FE decreased when AH was added $(P=0.003)$ in the current research. However, Castells et al. (2012) did not find any differences in FE in dairy calves fed different forage types. In the current research, calves fed the $5 \% \mathrm{AH}, 10 \% \mathrm{AH}$, and $10 \% \mathrm{AH}+$ Pro diets exhibited decreased $(P<0.01)$ values of FE compared with those fed the control and Pro diets. In addition, calves fed 5\%AH + Pro showed greater $(P<0.05) \mathrm{FE}$ than those fed the $5 \% \mathrm{AH}$ or $10 \% \mathrm{AH}$ diets. 
A) Caudodorsal sac

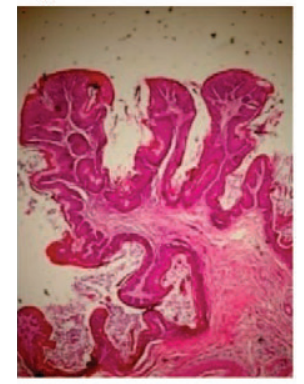

Control

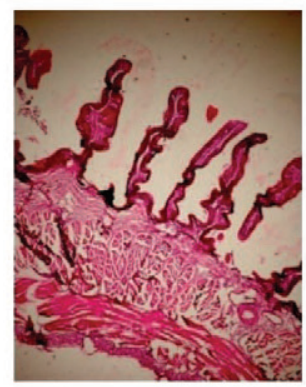

$10 \% \mathrm{AH}$

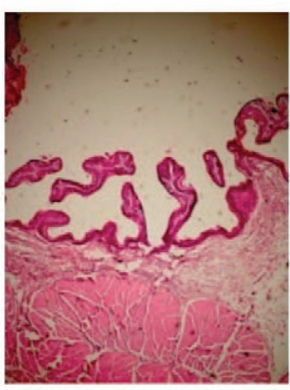

$10 \% \mathrm{AH}+$ Pro

C) Cranial part of the ventral sac

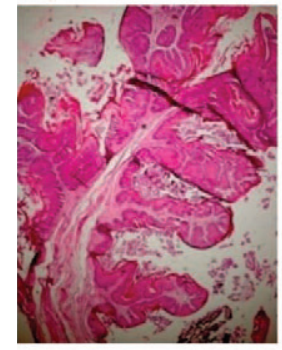

Control

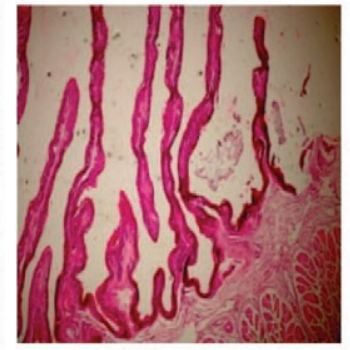

$10 \% \mathrm{AH}$

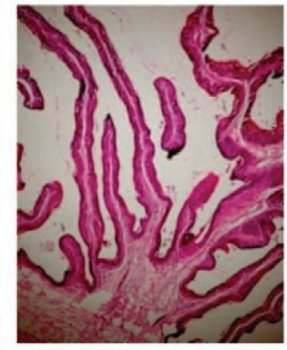

$10 \% \mathrm{AH}+$ Pro

B) Cranial part of the dorsal sac

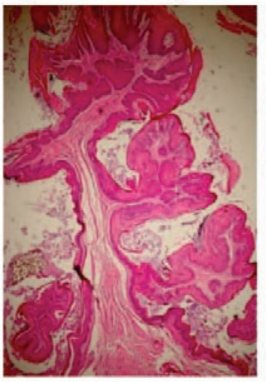

Control

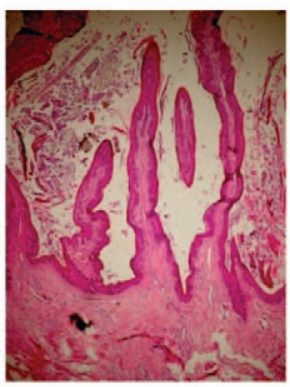

$10 \% \mathrm{AH}$

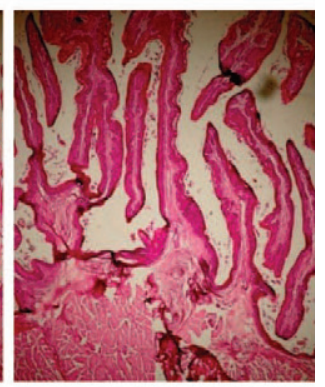

$10 \% \mathrm{AH}+$ Pro

D) Caudal portion of the caudoventral blind sac

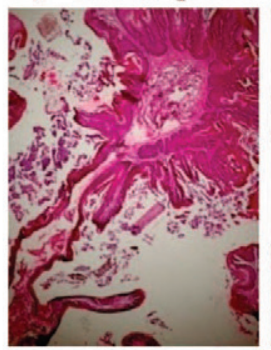

Control

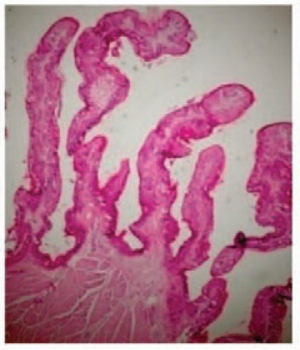

$10 \% \mathrm{AH}$

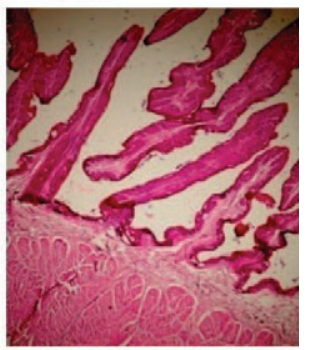

$10 \% \mathrm{AH}+$ Pro

E) Ventral portion of caudoventral blind sac

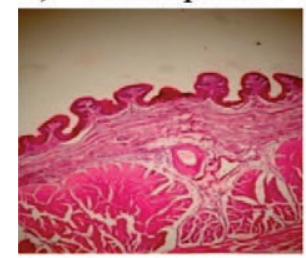

Control

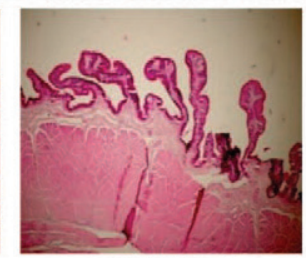

$10 \% \mathrm{AH}$

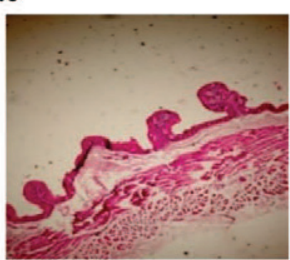

$10 \% \mathrm{AH}+$ Pro

Figure 2. Photomicrographs from all part of rumen bags of selected treatments. A) Caudodorsal sac; B) cranial part of dorsal sac; C) cranial part of ventral sac; D) caudal portion of caudoventral blind sac; E) ventral portion of caudoventral blind sac. Control = concentrate only with no forage or sodium propionate supplemented; $10 \% \mathrm{AH}=$ concentrate $+10 \%$ alfalfa hay; $10 \% \mathrm{AH}+$ Pro $=$ concentrate $+10 \%$ alfalfa hay $+5 \%$ sodium propionate. All sections of the ruminal papillae were stained with hematoxylin and eosin $(160 \times)$. Color version available in the online PDF.

Weaning age was significantly affected $(P<0.01)$ by $\mathrm{AH}$, with earlier weaning days observed for $5 \% \mathrm{AH}$, $10 \% \mathrm{AH}$, and $10 \% \mathrm{AH}+$ Pro treatments compared with control, Pro, and 5\% AH + Pro treatments. In contrast to these results, Coverdale et al. (2004) and Porter et al. (2007) reported no differences in the weaning age of dairy calves fed either low or high levels of grass hay and beet pulp. Klein et al. (1987) concluded that consumption of concentrate and roughage together with water at an early age was fundamentally important for both rumen maturation and weaning. In addition, Quigley (1996) stated that the 3 factors involved in weaning were age, BW, and DMI. Despite the positive effect of $\mathrm{AH}$ on DMI, not only in wk 1 to 6 but also during the whole $70 \mathrm{~d}$ of the current experiment, the reduced weaning age in $\mathrm{AH}$-fed calves in our study might have been due to the earlier and greater DMI allowing early establishment of rumen fermentation and supporting greater amounts of specific VFA for developing rumen epithelium.

The structural growth measures are presented in Table 3. Clearly, alfalfa had no effect on body length, hip height, or hip width; this finding is not consistent with that reported by Hill et al. (2008), who found a linear decline in hip width as hay percentage increased in their experimental diets.

\section{Effects of $\mathrm{AH}$ on Ruminal $\mathrm{pH}$ and Fermentation Characteristics}

According to the ruminal fermentation characteristics presented in Table $4, \mathrm{pH}$ values of sampled rumen fluid were within the range of those previously reported (Khan et al., 2008, 2011). Ruminal pH on d 35 was less $(P<0.05)$ in calves fed the Pro diet than in those fed the $10 \% \mathrm{AH}, 10 \% \mathrm{AH}+$ Pro, and $5 \% \mathrm{AH}+$ Pro diets 
Table 2. Dry matter intake, ADG, feed efficiency, weaning day, weaning weight, and final weights as influenced by dietary alfalfa hay and sodium propionate supplementation

\begin{tabular}{|c|c|c|c|c|c|c|c|c|c|c|}
\hline \multirow[b]{2}{*}{ Parameter } & \multicolumn{6}{|c|}{ Treatment $^{1}$} & \multirow[b]{2}{*}{ SEM } & \multicolumn{3}{|c|}{$P$-value } \\
\hline & Control & Pro & $5 \% \mathrm{AH}$ & $\begin{array}{l}5 \% \mathrm{AH} \\
+ \text { Pro }\end{array}$ & $10 \% \mathrm{AH}$ & $\begin{array}{l}10 \% \mathrm{AH} \\
+ \text { Pro }\end{array}$ & & $\begin{array}{l}\text { Forage } \\
(\mathrm{F})\end{array}$ & $\begin{array}{l}\text { Propionate } \\
\text { (P) }\end{array}$ & $\mathrm{F} \times \mathrm{P}$ \\
\hline $\begin{array}{l}\text { Starter intake, } \mathrm{kg} / \mathrm{d} \\
\text { wk } 1 \text { to } 6\end{array}$ & \multicolumn{8}{|c|}{ Starter intake, $\mathrm{kg} / \mathrm{d}$} & 0.49 & 0.95 \\
\hline wk 7 to 10 & $1.72^{\mathrm{bcd}}$ & $1.58^{\mathrm{d}}$ & $2.04^{\mathrm{abc}}$ & $1.70^{\mathrm{cd}}$ & $2.07^{\mathrm{ab}}$ & $2.44^{\mathrm{a}}$ & 0.13 & $<0.01$ & 0.74 & 0.04 \\
\hline wk 1 to 10 & $0.89^{\mathrm{b}}$ & $0.81^{\mathrm{b}}$ & $1.08^{\mathrm{ab}}$ & $0.90^{\mathrm{b}}$ & $1.12^{\mathrm{a}}$ & $1.25^{\mathrm{a}}$ & 0.07 & $<0.01$ & 0.46 & 0.13 \\
\hline wk 7 to 10 & $0.74^{\mathrm{b}}$ & $0.72^{\mathrm{b}}$ & $0.77^{\mathrm{ab}}$ & $0.78^{\mathrm{ab}}$ & $0.85^{\mathrm{ab}}$ & $0.90^{\mathrm{a}}$ & 0.05 & 0.03 & 0.72 & 0.76 \\
\hline wk 1 to 10 & $0.56^{\mathrm{ab}}$ & $0.52^{\mathrm{b}}$ & $0.50^{\mathrm{b}}$ & $0.53^{\mathrm{ab}}$ & $0.57^{\mathrm{ab}}$ & $0.60^{\mathrm{a}}$ & 0.02 & 0.05 & 0.72 & 0.32 \\
\hline \multicolumn{11}{|l|}{ Feed efficiency } \\
\hline wk 1 to 6 & $0.48^{\mathrm{a}}$ & $0.47^{\mathrm{ab}}$ & $0.36^{\mathrm{bc}}$ & $0.42^{\mathrm{ab}}$ & $0.32^{c}$ & $0.41^{\mathrm{ab}}$ & 0.03 & 0.01 & 0.09 & 0.30 \\
\hline wk 7 to 10 & $0.35^{\mathrm{ab}}$ & $0.38^{\mathrm{a}}$ & $0.29^{\mathrm{b}}$ & $0.39^{\mathrm{a}}$ & $0.35^{\mathrm{ab}}$ & $0.27^{\mathrm{b}}$ & 0.02 & 0.19 & 0.36 & $<0.01$ \\
\hline wk 1 to 10 & $0.42^{\mathrm{a}}$ & $0.43^{\mathrm{a}}$ & $0.33^{\mathrm{c}}$ & $0.41^{\mathrm{ab}}$ & $0.33^{\mathrm{c}}$ & $0.35^{\mathrm{bc}}$ & 0.02 & $<0.01$ & 0.08 & 0.25 \\
\hline Weaning day & $57^{\mathrm{a}}$ & $61^{\mathrm{a}}$ & $46^{\mathrm{b}}$ & $59^{\mathrm{a}}$ & $45^{\mathrm{b}}$ & $47^{\mathrm{b}}$ & 2.70 & $<0.01$ & 0.01 & 0.09 \\
\hline
\end{tabular}

${ }^{\mathrm{a}-\mathrm{d}}$ Means within a row with different superscripts differ $(P<0.05)$.

${ }^{1} \mathrm{Control}=$ concentrate only with no forage and sodium propionate supplemented; Pro $=$ concentrate $+5 \%$ sodium propionate; $5 \% \mathrm{AH}=$ concentrate $+5 \%$ alfalfa hay; $5 \% \mathrm{AH}+$ Pro $=$ concentrate $+5 \%$ alfalfa hay $+5 \%$ sodium propionate $; 10 \% \mathrm{AH}=$ concentrate $+10 \%$ alfalfa hay; $10 \% \mathrm{AH}+$ Pro $=$ concentrate $+10 \%$ alfalfa hay $+5 \%$ sodium propionate.

(5.36 vs. $5.79,5.79$, and 5.89, respectively). Moreover, ruminal $\mathrm{pH}$ values on $\mathrm{d} 70$ were less $(P<0.05)$ in calves fed control, $5 \% \mathrm{AH}$, and 5\% AH + Pro diets $(5.66,5.85$, and 5.85 , respectively) than for those fed the $10 \% \mathrm{AH}$ diet (6.27). Higher ruminal $\mathrm{pH}$ in calves fed the $10 \% \mathrm{AH}$ diet could be attributed to better rumen conditions, which contribute to increased levels of mastication and salivary flow and suitable VFA blends with lower propionate levels (Khan et al., 2008, 2011). Total VFA concentration was not affected by $\mathrm{AH}$ provision on $\mathrm{d}$ 35 , but was greater $(P<0.01)$ on d 70 . Alfalfa hay inclusion increased $(P<0.05)$ acetate concentration on d 35 and 70 of the experimental period and tended to increase $(P=0.09)$ the molar proportion of butyrate on d 35 but not on d 70 . We observed no significant effects of $\mathrm{AH}$ on the molar proportion of propionate or on the acetate:propionate ratio (Table 4). The higher ruminal total VFA concentrations in calves fed the $10 \% \mathrm{AH}$ diet compared with those fed the control, Pro, or $5 \% \mathrm{AH}+$ Pro diets might have been associated with the greater solid feed consumption during the experimental period, the (likely) earlier establishment of ruminal microbes, and better fermentation of OM (Baldwin et al., 2004; Khan et al., 2008; Li et al., 2012).

Table 3. Structural growth parameters in calves fed the different diets ${ }^{1}$

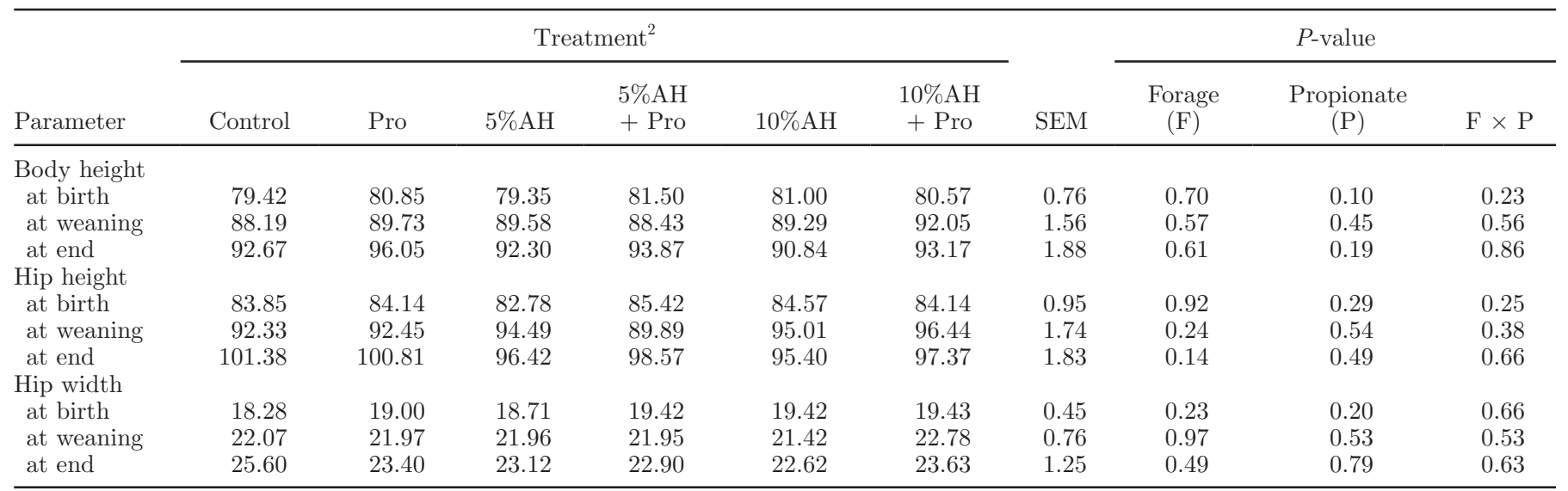

${ }^{1}$ Statistical significance was declared at probabilities $P<0.05$.

${ }^{2} \mathrm{Control}=$ concentrate only with no forage and sodium propionate supplemented; Pro $=$ concentrate $+5 \%$ sodium propionate; $5 \% \mathrm{AH}=$ concentrate $+5 \%$ alfalfa hay; $5 \% \mathrm{AH}+$ Pro $=$ concentrate $+5 \%$ alfalfa hay $+5 \%$ sodium propionate; $10 \% \mathrm{AH}=$ concentrate $+10 \%$ alfalfa hay; $10 \% \mathrm{AH}+$ Pro $=$ concentrate $+10 \%$ alfalfa hay $+5 \%$ sodium propionate. 
Table 4. Ruminal $\mathrm{pH}$ and VFA concentration $(\mathrm{m} M)$ measured at d 35 and 70 in calves receiving different starter diets

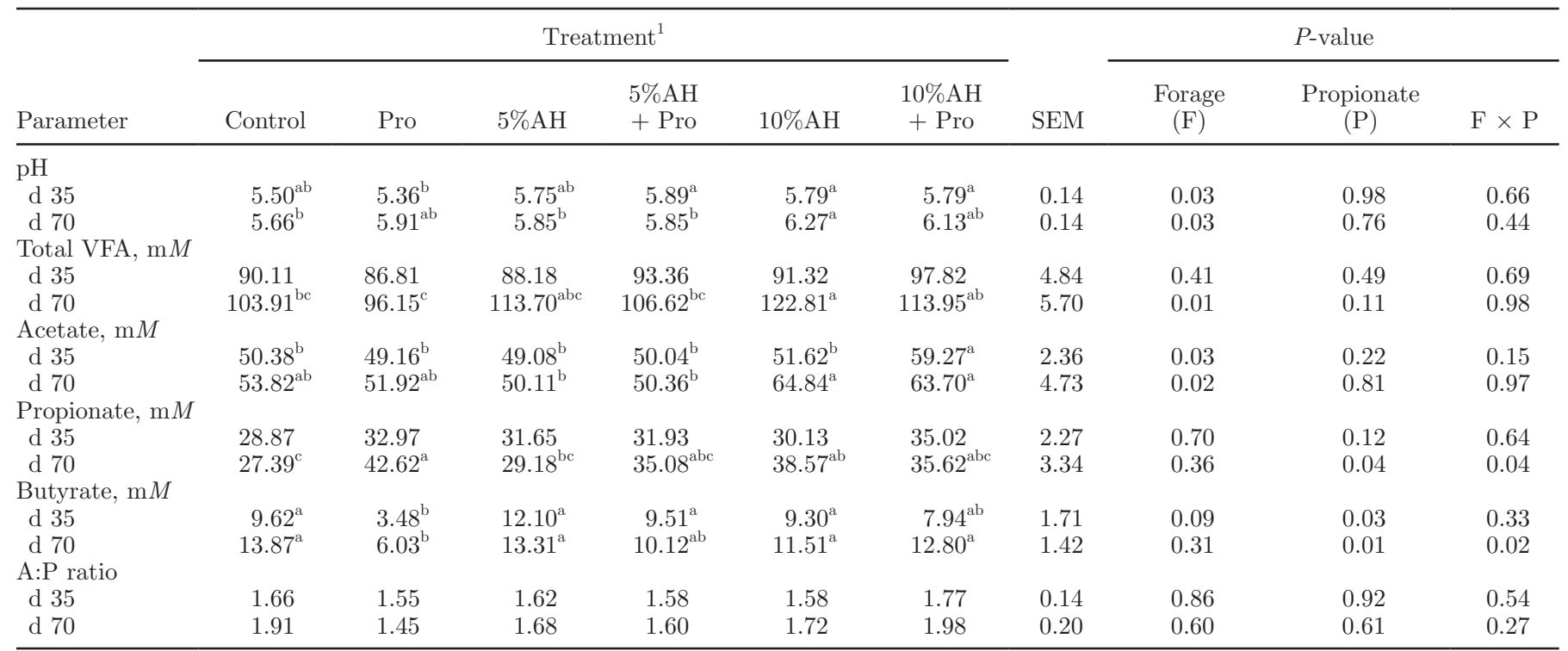

${ }^{\mathrm{a}-\mathrm{c}}$ Means within a row with different superscripts differ $(P<0.05)$.

${ }^{1} \mathrm{Control}=$ concentrate only with no forage and sodium propionate supplemented; Pro $=$ concentrate $+5 \%$ sodium propionate; $5 \% \mathrm{AH}=$ concentrate $+5 \%$ alfalfa hay $; 5 \% \mathrm{AH}+$ Pro $=$ concentrate $+5 \%$ alfalfa hay $+5 \%$ sodium propionate $; 10 \% \mathrm{AH}=$ concentrate $+10 \%$ alfalfa hay; $10 \% \mathrm{AH}+$ Pro $=$ concentrate $+10 \%$ alfalfa hay $+5 \%$ sodium propionate.

\section{Effects of Pro on Performance}

Inclusion of sodium propionate in diets had no effect $(P>0.10)$ on DMI, ADG, or weaning and final weights during the experimental period (Table 2). Our results were in agreement with those obtained by Ferreira and Bittar (2011), who reported that inclusion of calcium propionate in the diet of dairy calves had no effect on DMI, ADG, or weaning and final weights. Feed efficiency tended to increase $(P=0.08)$ and was greater in calves fed the control, Pro, and 5\% AH + Pro diets than in calves fed the other treatments. Lee-Rangel et al. (2012) reported that inclusion of calcium propionate in the diets of lambs had no effect on their feed conversion. These observations suggest that the ME supplied by VFA is more efficiently utilized than the same amount of ME supplied by the diet (Poole and Allen, 1970). Inclusion of sodium propionate in diets increased $(P$ $=0.01$ ) weaning age in the current study. In addition, weaning and final measures of skeletal growth were not affected $(P>0.10)$ by sodium propionate inclusion in the diets (Tables 2 and 3). These results are consistent with those of Ferreira and Bittar (2011), who reported that calves fed calcium propionate and sodium butyrate exhibited skeletal growth measures similar to those of the control group.

\section{Effects of Pro on Ruminal pH and Fermentation Characteristics}

Inclusion of sodium propionate in diets had no effect $(P>0.10)$ on ruminal $\mathrm{pH}$, total VFA, acetate, or

Table 5. Effects of the 3 selected diets on rumen tissue parameters

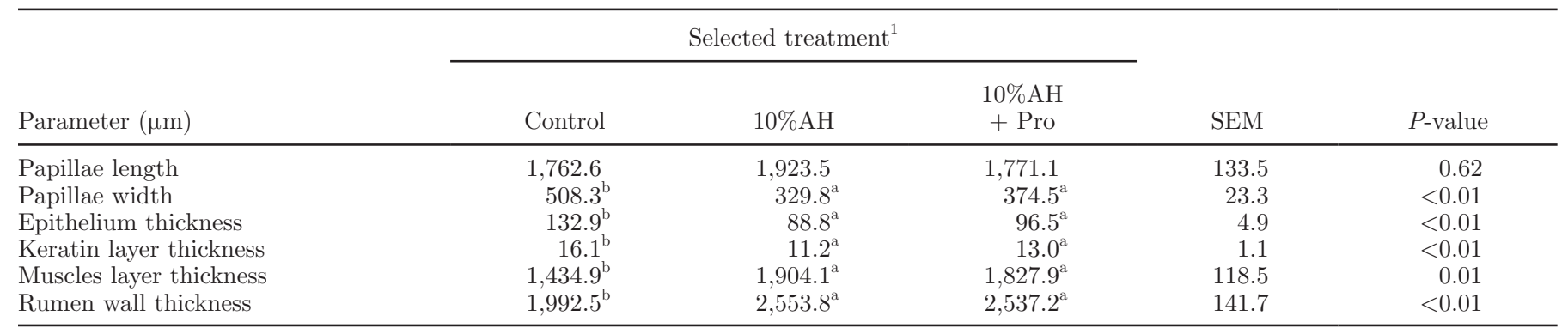

${ }^{\mathrm{a}, \mathrm{b}}$ Means within a row with different superscripts differ $(P<0.05)$.

${ }^{1}$ Control $=$ concentrate only with no forage and sodium propionate supplemented; $10 \% \mathrm{AH}=$ concentrate $+10 \%$ alfalfa hay; $10 \% \mathrm{AH}+$ Pro $=$ concentrate $+10 \%$ alfalfa hay $+5 \%$ sodium propionate. 


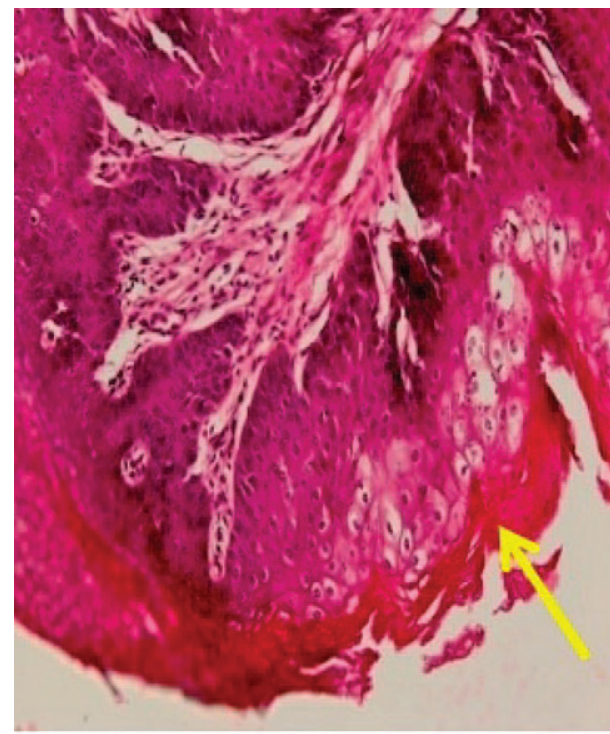

Control

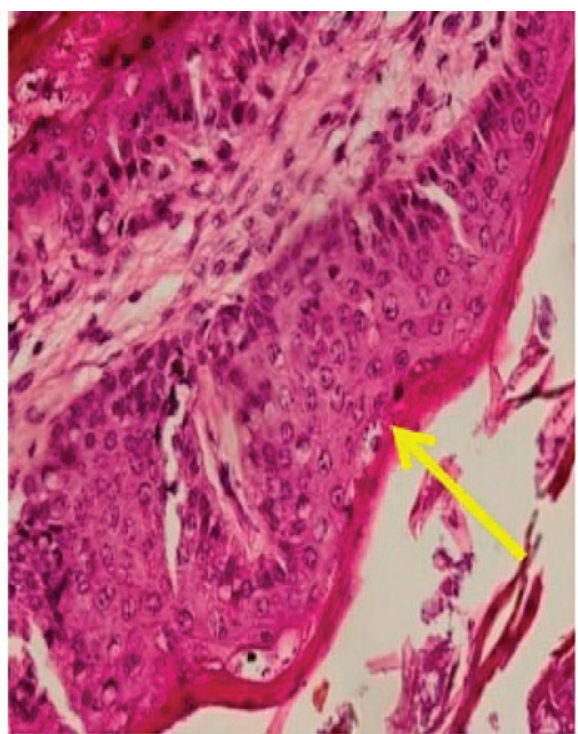

$10 \% \mathrm{AH}$

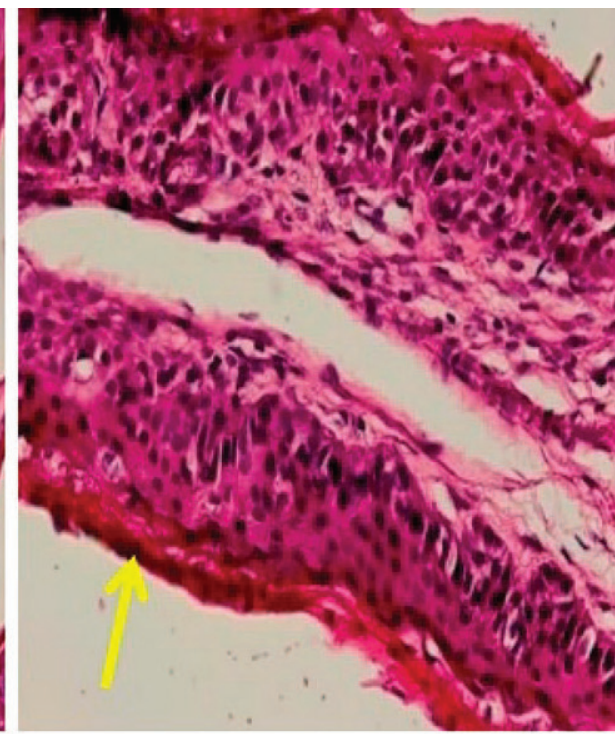

$10 \% \mathrm{AH}+$ Pro

Figure 3. Papilla keratin layer (arrows) from rumen of selected treatments. Control = concentrate only with no forage or sodium propionate supplemented; $10 \% \mathrm{AH}=$ concentrate $+10 \%$ alfalfa hay; $10 \% \mathrm{AH}+$ Pro $=$ concentrate $+10 \%$ alfalfa hay $+5 \%$ sodium propionate Color version available in the online PDF.

acetate:propionate ratio (Table 4). The molar proportion of ruminal propionate on d 35 was also similar across the treatments. However, the highest ruminal propionate concentrations were observed for the Pro treatment on d 70, which was similar to the level observed by Suárez et al. (2006). They reported that the molar proportion of propionate was $>27 \%$ when veal calves were fed various concentrates. The increased propionate concentration observed in the rumen of calves fed the Pro diet may be attributed to the supplemental sodium propionate in the diet (Majdoub et al., 2003). Inclusion of sodium propionate in diets decreased $(P<$ $0.05)$ the molar proportion of ruminal butyrate on $\mathrm{d} 35$ and 70 of the experimental period (Table 4). The lowest ruminal butyrate concentrations among the treatments were observed for the Pro diet. These results are in agreement with those of Majdoub et al. (2003), who observed lower butyrate concentrations when propionate was infused into the rumen of growing lambs, perhaps because of a small decline in the protozoa population in the rumen.

\section{Effects of $\mathrm{AH}$ and Pro Interaction on Performance}

An interaction was observed between $\mathrm{AH}$ and Pro for DMI $(\mathrm{kg} / \mathrm{d})$ from wk 7 to $10(P=0.04)$. Dry matter intake increased $(P<0.05)$ when propionate was added to the high-forage diets $(10 \% \mathrm{AH}+$ Pro) but decreased $(P<0.05)$ when propionate was added to the lowforage diets or those without forage (Pro and $5 \% \mathrm{AH}$
+ Pro; Table 2). Increased DMI has been reported for forage mixed diets (Coverdale et al., 2004; Khan et al., 2011; Castells et al., 2012) but not for VFA salts (specifically propionate salts; Lane and Jesse, 1997; Ferreira and Bittar, 2011; Lee-Rangel et al., 2012). The AH $\times$ Pro interaction in calves offered the $10 \% \mathrm{AH}+$ Pro diet may have improved the rumen environment, which, in turn, may have contributed to the stimulation of starter intake. Simultaneous administration of $\mathrm{AH}$ with Pro did not affect $(P>0.10)$ ADG or weaning and final weights, but decreased $(P<0.01) \mathrm{FE}$ from wk 7 to 10 . Moreover, weaning day tended to increase $(P=0.08)$ as a result of the $\mathrm{AH} \times$ Pro interaction. Previous studies have shown that higher DMI levels increase passage rate (Dijkstra et al., 2002), which could decrease digestibility of OM (Castells et al., 2012). Therefore, the higher $\mathrm{DMI}$ in calves fed the AH diets may be associated with the lower FE. In addition, we observed no interactions during the experimental period between $\mathrm{AH}$ and Pro with respect to structural growth parameters (Table 3 ).

\section{Effects of $\mathrm{AH}$ and Pro Interaction on Rumen Fermentation Characteristics}

We observed no interactions between $\mathrm{AH}$ and Pro on ruminal $\mathrm{pH}$, total VFA, molar proportions of acetate or propionate, or acetate:propionate ratio (Table 4). We observed an interaction of the molar proportion of butyrate on d $70(P=0.02)$ with $\mathrm{AH}$ and Pro. Changes in ruminal butyrate concentration were observed when 


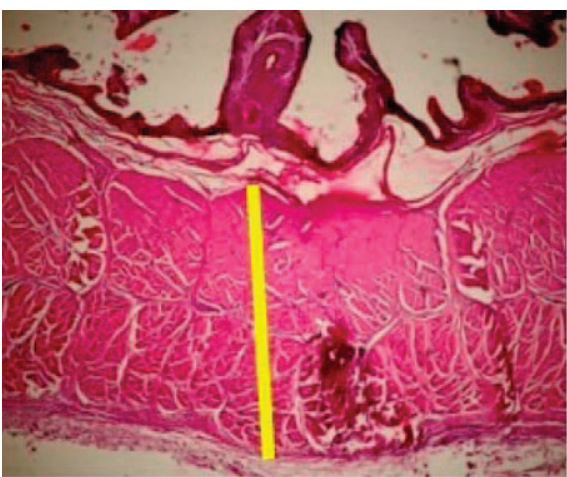

Control

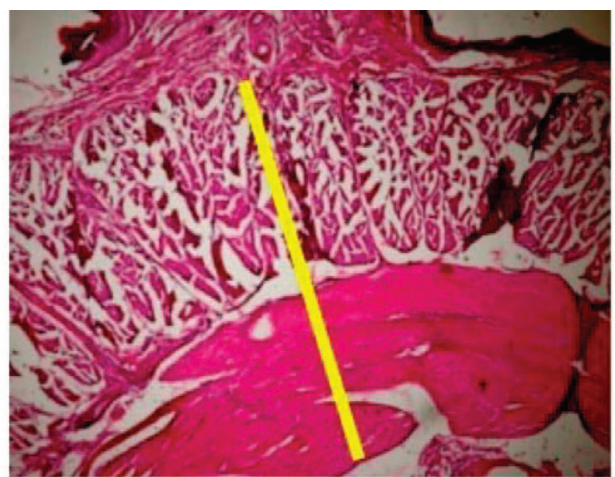

$10 \% \mathrm{AH}$

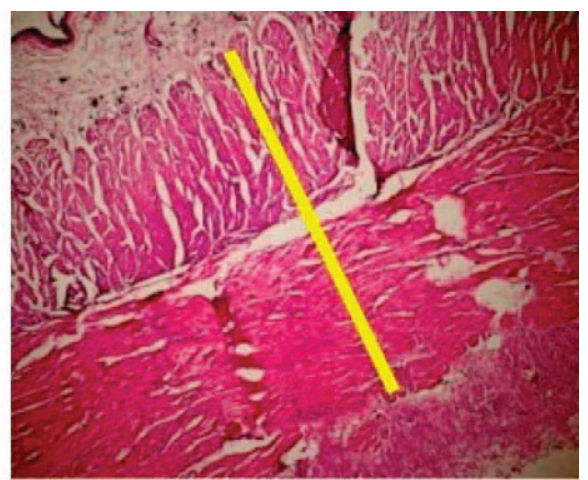

$10 \% \mathrm{AH}+$ Pro

Figure 4. Rumen muscles layer from cranial ventral sac of rumen of selected treatments. Control $=$ concentrate only with no forage or sodium propionate supplemented; $10 \% \mathrm{AH}=$ concentrate $+10 \%$ alfalfa hay; $10 \% \mathrm{AH}+$ Pro $=$ concentrate $+10 \%$ alfalfa hay $+5 \%$ sodium propionate. Color version available in the online PDF.

different forage-to-concentrate ratios were offered to young calves (Žitnan et al, 1998). However, no similar published data are available for comparison.

\section{Macroscopic and Microscopic Evaluation of the Rumen Wall}

Representative images of the rumen wall are shown in Figure 3, and the associated morphometric parameters are presented in Table 5. The rumen mucosa of calves fed the control diet show focal or multifocal patches with coalescing and adhering papillae covered by a sticky mass of feed, hair, and cell debris. Rumen images from calves in the $10 \% \mathrm{AH}$ and $10 \% \mathrm{AH}+$ Pro treatments showed excellent rumen mucosa development with a healthy coloration associated with proper microbial fermentation and increased mucosa development up to $10 \mathrm{wk}$ of age. Limited pitches are also observed in the rumen wall of calves fed the $10 \% \mathrm{AH}+$ Pro diet.

Although rumen wall papillae length (varying between 1,763 and $1,924 \mu \mathrm{m})$ was not affected $(P>0.10)$ by the dietary treatments, papillae width decreased $(P$ $<0.01$ ) in calves fed the $10 \% \mathrm{AH}$ and $10 \% \mathrm{AH}+$ Pro diets compared with those fed the control diet. Calves fed the $10 \% \mathrm{AH}$ and $10 \% \mathrm{AH}+$ Pro diets also had thinner $(P<0.01)$ rumen epithelium and keratin layer thicknesses than those fed the control diet (Figure 3). Moreover, calves fed the control diet had thinner $(P<$ $0.01)$ muscle layers and decreased $(P<0.01)$ rumen wall thicknesses than those fed the other treatments (Table 5, Figure 4). Microscopic views of papillae from different rumen bags of calves fed the selected diets are shown in Figure 2 and those from calves fed the control diet are shown in Figure 5. Similar to our findings, Nocek (1997) and Suárez et al. (2007) reported that calves fed a starter diet without forage exhibited greater levels of plaque formation when judged macroscopically than did control calves. Gäbel et al. (1987) observed that the number of cell layers present in the stratum corneum (keratin layer) was highly dependent on the dietary composition, noting as many as 15 cell layers in thickness when concentrate diets were fed or
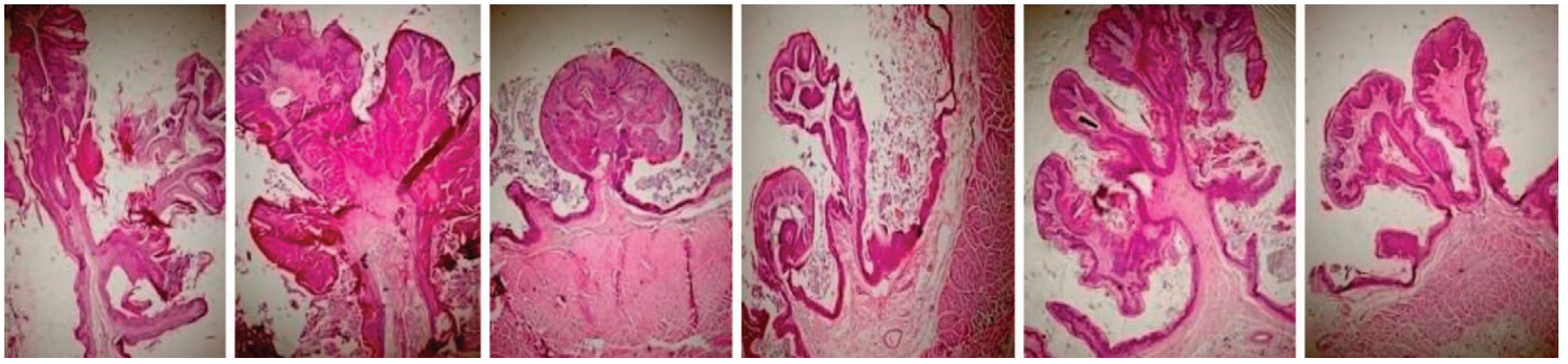

Figure 5. Deformation papillae from different bags of rumen tissue of calves fed the control diet (concentrate only with no forage or sodium propionate supplemented). Sections of ruminal papillae were stained with hematoxylin and eosin $(160 \times)$. Color version available in the online PDF. 
fewer than 4 layers when roughage diets were fed. The thinner keratin layer in the papilla of calves fed the forage mixed starter could be attributed to the abrasive effects of forage (Figure 3). The higher values of rumen wall and muscle layer thicknesses observed in calves fed the starter diet with $\mathrm{AH}$ could be attributed to the higher DMI, which can induce greater motility and contractions of the rumen wall due to the forage portion of the starter, thereby giving rise to bulkier and stronger rumen muscles. These results are in agreement with those of Beharka et al. (1998), who reported that physical stimulation by solid feed was needed, not only for the proper development of muscle layers but also for ruminal motility. Similarly, Harrison et al. (1960) demonstrated that calves fed sawdust had $168 \%$ greater muscle development in the rumen than those fed only milk. In our experiment, calves fed the $10 \% \mathrm{AH}$ and $10 \% \mathrm{AH}+$ Pro diets consumed sufficient DMI to achieve normal rumen development. It is well established that deformed or branching papillae occur due to the effect of uncontrolled ruminal butyrate and propionate on cell proliferations. Our results are in agreement with those of Beharka et al. (1998) and Mentschel et al. (2001). They reported that the greater mitotic index of papilla epithelium in the rumen of calves fed ground diets or diets containing butyrate and propionate might be caused by induced cell proliferation as a strategy to increase the branching or surface area. As shown in calves fed the control diet in the current study, starter diets lacking in components with abrasive properties could result in aggregation of dead cells on the papillae and the formation of keratinized layers, which would eventually lead to parakeratosis.

\section{CONCLUSIONS}

Feeding AH increased overall DMI, ADG, and final weight, thereby shortening the time to weaning. This effect of forage was attributable, in part, to its physical property (abrasion effect), which leads to reduced plaque formation in the rumen wall and improves the macroscopic and microscopic appearance of the rumen. However, regardless of the level of $\mathrm{AH}$ included in the diet, FE was reduced over the entire experimental period. Supplementing propionate had no effect on performance but did increase weaning age; this might be attributed to the reduced molar proportion of butyrate. Except for the molar proportion of butyrate, we observed no interactions between dietary forage and sodium propionate on performance, skeletal growth, or rumen fermentation characteristics at the end of the experimental period. Forage (physical factor) had a more effective role than sodium propionate (chemical factor) on calf performance and rumen development under current feeding conditions.

\section{ACKNOWLEDGMENTS}

FKA Agri.-Animal Production Co. (Isfahan, Iran) is acknowledged for their partial funding of this study. J. Jalilnejad (FKA Agri.-Animal Production Co., Isfahan, Iran) is also appreciated for his assistance throughout the experiments. Isfahan University of Technology (IUT) receives our deep gratitude for the financial support extended to us. Mohammad Ariana (Khorram-Abad Azad Islamic University), Mehdi Mirzaei, Azizollah Bakhtari, Farzad Hashemzadeh-Cigari, Nahid Pezhveh, Sayed Mahmoud Reihani-e-Rostami, Hamid-Reza Moeinoddini, Jalal Boka, Farhad Mohammad-Panah (all from IUT, Isfahan, Iran), and Saideh Omidian (FKA Agri-Animal Production Co.) deserve our thanks for their helpful technical assistance in conducting the experiments. The authors also express their appreciation to Ezzatollah Roustazadeh (IUT) and Clayton Stoffel, Dave Combs, and Heather White (all from University of Wisconsin-Madison) for editing the final English version of this manuscript.

\section{REFERENCES}

Baldwin, R. L., K. R. McLeod, and J. L. Klitz. 2004. Rumen development, intestinal growth and hepatic metabolism in the pre- and postweaning ruminant. J. Dairy Sci. 87:55-65.

Beharka, A. A., T. G. Nagaraja, J. L. Morrill, G. A. Kennedy, and R. D. Klemm. 1998. Effects of form of the diet on anatomical, microbial, and fermentative development of the rumen of neonatal calves. J. Dairy Sci. 81:1946-1955.

Castells, L., A. Bach, G. Araujo, C. Montoro, and M. Terré. 2012. Effect of different forage sources on performance and feeding behavior of Holstein calves . J. Dairy Sci. 95:286-293.

Coverdale, J. A., H. D. Tyler, J. D. Quigley, and J. A. Brumm. 2004. Effect of various levels of forage and form of diet on rumen development and growth in calves. J. Dairy Sci. 87:2554-2562.

Dijkstra, J., J. A. N. Mills, and J. France. 2002. The role of dynamic modelling in understanding the microbial contribution to rumen function. Nutr. Res. Rev. 15:67-90.

Ferreira, L. S., and C. M. M. Bittar. 2011. Performance and plasma metabolites of dairy calves fed starter containing sodium butyrate, calcium propionate or sodium monensin. Animal 5:239-245. http://dx.doi.org/10.1017/S1751731110001965.

Flatt, W. P., R. G. Warner, and J. K. Loosli. 1958. Influence of purified materials on the development of the ruminant stomach. J. Dairy Sci. 14:1593-1600.

Gäbel, G., H. Martens, M. Suendermann, and P. Gálfi. 1987. The effect of diet, intraruminal $\mathrm{pH}$ and osmolarity on sodium, chloride and magnesium absorption from the temporarily isolated and washed reticulo-rumen of sheep. Q. J. Exp. Physiol. 72:501-511.

Harrison, H. N., R. G. Warner, E. G. Sander, and J. K. Loosli. 1960. Changes in the tissue and volume of the stomachs of calves following removal of dry feed or consumption of inert bulk. J. Dairy Sci. 43:1301-1312.

Hill, T. M., H. G. Bateman, J. M. Aldrich, and R. L. Schlotterbeck. 2008. Effects of the amount of chopped hay or cottonseed hulls in a textured calf starter on young calf performance. J. Dairy Sci. 91:2684-2693.

Hill, T. M., H. G. Bateman, J. M. Aldrich, and R. L. Schlotterbeck. 2009. Roughage for diets fed to weaned dairy calves. Prof. Anim. Sci. 25:283-288.

Hill, T. M., H. G. Bateman, J. M. Aldrich, and R. L. Schlotterbeck. 2010. Roughage amount, source, and processing for diets fed to weaned dairy calves. Prof. Anim. Sci. 26:181-187. 
Iranian Council of Animal Care. 1995. Guide to the Care and Use of Experimental Animals, 1. Isfahan University of Technology, Isfahan, Iran.

Khan, M. A., H. J. Lee, W. S. Lee, H. S. Kim, S. B. Kim, S. B. Park, K. S. Baek, J. K. Ha, and Y. J. Choi. 2008. Starch source evaluation in calf starter: II. Ruminal parameters, rumen development, nutrient digestibilities, and nitrogen utilization in Holstein calves. J. Dairy Sci. 91:1140-1149.

Khan, M. A., D. M. Weary, and M. A. G. von Keyserlingk. 2011. Hay intake improves performance and rumen development of calves fed higher quantities of milk. J. Dairy Sci. 94:3547-3553.

Klein, R. D., R. L. Kincaid, A. S. Hodgson, J. H. Harrison, J. K. Hillers, and J. D. Cronrath. 1987. Dietary fiber and early weaning on growth and rumen development of calves. J. Dairy Sci. 70:2095-2104.

Lane, M. A., and B. W. Jesse. 1997. Effect of volatile fatty acid infusion on development of the rumen epithelium in neonatal sheep. J. Dairy Sci. 80:740-746.

Lee-Rangel, H. A., G. D. Mendoza, and S. S. González. 2012. Effect of calcium propionate and sorghum level on lamb performance. Anim. Feed Sci. Technol. 177:237-241.

Lesmeister, K. E., and A. J. Heinrichs. 2005. Effects of adding extra molasses to a texturized calf starter on rumen development, growth characteristics, and blood parameters in neonatal dairy calves. J. Dairy Sci. 88:411-418.

Lesmeister, K. E., P. R. Tozer, and A. J. Heinrichs. 2004. Development and analysis of a rumen tissue sampling procedure. J. Dairy Sci. 87:1336-1344.

Li, R. W., E. E. Connor, C. Li, R. L. Baldwin, and M. E. Sparks. 2012. Characterization of the rumen microbiota of pre-ruminant calves using metagenomic tool semi. Environ. Microbiol. 14:129-139.

Liu, Q., C. Wang, W. Z. Yang, G. Guo, X. M. Yang, D. C. He, K. H. Dong, and Y. X. Huang. 2010. Effects of calcium propionate supplementation on lactation performance, energy balance and blood metabolites in early lactation dairy cows. J. Anim. Physiol. Anim. Nutr. (Berl.) 94:605-614

Majdoub, L., M. Vermorel, and I. Ortigues-Marty. 2003. Intra-ruminal propionate supplementation modifies hindlimb energy metabolism without changing the splanchnic release of glucose in growing lambs. Br. J. Nutr. 89:39-50.
Mentschel, J., R. Leiser, C. Mülling, C. Pfarrer, and R. Claus. 2001. Butyric acid stimulates rumen mucosa development in the calf mainly by a reduction of apoptosis. Arch. Tierernahr. 55:85-102.

NRC. 2001. Nutrient Requirements of Dairy Cattle. 7th rev. ed. Natl Acad. Sci., Washington, DC.

Nocek, J. E. 1997. Bovine acidosis: Implications on laminitis. J. Dairy Sci. 80:1005-1028.

Peiris, H., R. Elliott, and B. W. Norton. 1998. Supplementary grain and sodium propionate increase the live weight gain and glucose entry rates of steers given molasses diets. J. Agric. Sci. (Camb.) 130:205-211.

Poole, D. A., and D. M. Allen. 1970. Utilization of salts of volatile fatty acids by growing sheep. Br. J. Nutr. 24:695-704.

Porter, J. C., R. G. Warner, and A. F. Kertz. 2007. Effect of fiber level and physical form of starter on growth and development of dairy calves fed no forage. Prof. Anim. Sci. 23:395-400.

Quigley, J. D. 1996. Influence of weaning method on growth, intake, and selected blood metabolites in Jersey calves. J. Dairy Sci $79: 2255-2260$

Suárez, B. J., C. G. V. Reenen, N. Stockhofe, J. Dijkstra, and W. J. J. Gerrits. 2007. Effect of roughage source and roughage to concentrate ratio on animal performance and rumen development in veal calves. J. Dairy Sci. 90:2390-2403.

Suárez, B. J., C. G. Van Reenen, G. Beldman, J. van Delen, J. Dijkstra, and W. J. J. Gerrits. 2006. Effects of supplementing concentrates differing in carbohydrate composition in veal calf diets: I. Animal performance and rumen fermentation characteristics. J. Dairy Sci. 89:4365-4375.

Tamate, H., A. D. McGilliard, N. L. Jacobson, and R. Getty. 1962 Effect of various dietaries on the anatomical development of the stomach in the calf. J. Dairy Sci. 45:408-420.

van Ackerena, C., H. Steinga, K. Hartung, R. Funk, and W. Drochner. 2009. Effect of roughage level in a total mixed ration on feed intake, ruminal fermentation patterns and chewing activity of earlyweaned calves with ad libitum access to grass hay. Anim. Feed Sci Technol. 153:48-59.

Zitnan, R., J. Voigt, U. Schonhusen, J. Wegner, M. Kokardova, H. Hagemeister, M. Levkut, S. Kuhla, and A. Sommer. 1998. Influence of dietary concentrate to forage ratio on the development of rumen mucosa in calves. Arch. Tierernahr. 51:279-291. 